NBER WORKING PAPER SERIES

\title{
GIVE ME YOUR TIRED, YOUR POOR, YOUR HIGH-SKILLED LABOR: H-1B LOTTERY OUTCOMES AND ENTREPRENEURIAL SUCCESS
}

\author{
Stephen G. Dimmock \\ Jiekun Huang \\ Scott J. Weisbenner \\ Working Paper 26392 \\ http://www.nber.org/papers/w26392 \\ NATIONAL BUREAU OF ECONOMIC RESEARCH \\ 1050 Massachusetts Avenue \\ Cambridge, MA 02138 \\ October 2019
}

We thank Yunju Cha, Yu Sheng Loh, and Chunxue Yang for excellent research assistance. For helpful comments we thank Kai Li, Tim McQuade, seminar participants at Australia National University, and participants at the Western Finance Association Conference and the Red Rock Finance Conference. All opinions expressed are those of the authors and not the National Bureau of Economic Research.

At least one co-author has disclosed a financial relationship of potential relevance for this research. Further information is available online at http://www.nber.org/papers/w26392.ack

NBER working papers are circulated for discussion and comment purposes. They have not been peer-reviewed or been subject to the review by the NBER Board of Directors that accompanies official NBER publications.

(C) 2019 by Stephen G. Dimmock, Jiekun Huang, and Scott J. Weisbenner. All rights reserved. Short sections of text, not to exceed two paragraphs, may be quoted without explicit permission provided that full credit, including $(\odot)$ notice, is given to the source. 
Give Me Your Tired, Your Poor, Your High-Skilled Labor: H-1B Lottery Outcomes and Entrepreneurial Success

Stephen G. Dimmock, Jiekun Huang, and Scott J. Weisbenner

NBER Working Paper No. 26392

October 2019

JEL No. D22,G24,G32,J23,J24,J61,O3

\begin{abstract}
We study how access to high-skill labor affects the outcomes of start-up firms. We obtain exogenous variation in firms' ability to access skilled labor by using win rates in $\mathrm{H}-1 \mathrm{~B}$ visa lotteries. Relative to other firms that also applied for H-1B visas, firms with higher lottery win rates are more likely to receive additional venture capital funding and to have a successful exit via an IPO or acquisition. H-1B visa lottery winners also subsequently receive more patents and patent citations. Overall, our results show that access to high-skill labor is a critical determinant of success for start-up firms.

Stephen G. Dimmock

Division of Finance and Banking

Nanyang Technological University

Singapore

dimmock@ntu.edu.sg

Jiekun Huang

University of Illinois at Urbana-Champaign

Department of Finance

340 Wohlers Hall, MC-706

1206 South Sixth Street

Champaign, IL 61820

huangjk@illinois.edu

Scott J. Weisbenner

University of Illinois at Urbana-Champaign Department of Finance

340 Wohlers Hall, MC-706

1206 South Sixth Street

Champaign, IL 61820

and NBER

weisbenn@illinois.edu
\end{abstract}


There is considerable debate about the desirability of allowing high-skill foreign workers to enter the country. Proponents argue that there is a shortage of high-skilled labor, creating a need for foreign workers. Accordingly, access to high-skilled foreign workers may benefit domestic firms, increasing investment and innovation. Yet, critics contend that, instead of filling a skill gap, foreign workers merely displace American workers and have little effect on investment and innovation by firms. Despite the intense debate, there is little evidence on the effect of high-skill foreign workers on firm-level outcomes.

In the United States, firms can access high-skill foreign workers through the H-1B visa system. For each federal government fiscal year, there is a fixed quota of $\mathrm{H}-1 \mathrm{~B}$ visas available to for-profit firms. ${ }^{1}$ During years in which the demand for H-1B workers exceeds the available quota, the visas are allocated through a "lottery."2 These H-1B visa lotteries provide an ideal setting to identify the causal effect of highly skilled foreign workers on the success of firms. By exogenously varying the supply of $\mathrm{H}-1 \mathrm{~B}$ visas across firms that are ex ante similar, these lotteries enable us to isolate the effect of high-skilled foreign labor on firms' outcomes from confounding factors.

In this paper, we exploit exogenous variation in firms' H-1B visa lottery outcomes to identify how access to high-skill foreign workers affects the success of start-up firms. For such firms, high-skill workers can contribute to the success of the firm by increasing productivity and innovation as start-ups often depend heavily on the human capital of their employees. If high-

\footnotetext{
${ }^{1}$ The H-1B visa quota does not apply to hiring by universities and certain non-profit organizations. In this paper, we study for-profit firms that are subject to the quota.

${ }^{2}$ U.S. Citizenship and immigration Services uses “a computer-generated random selection process" to allocate H-1B visas when applications exceed the quota. For example, see https://www.uscis.gov/news/alerts/uscis-completes-h$\underline{1 \mathrm{~b}-\mathrm{cap}-\mathrm{random}-\text { selection-process-fy-2019. }}$
} 
skilled foreign workers are important for the development of start-up firms, other things equal, access to foreign talent should lead to better firm outcomes.

The success or failure of start-ups has significant economy-wide implications, making this an important group of firms to study. First, most large firms started as small firms and this paper thus examines how important obtaining high-skill labor is to entrepreneurial success. Second, innovation and technological progress are key drivers of economic growth (Romer, 1990; Aghion and Howitt, 1992). Work dating back to Schumpeter (1942) highlights the importance of start-ups in generating innovation and disruptive technologies. More recently, Gourio, Messer, and Siemer (2016) highlight how the number of start-ups in a region has an important role in explaining the region's long-term economic development.

We construct a sample of start-up firms in the Crunchbase dataset that filed $\mathrm{H}-1 \mathrm{~B}$ petitions for government fiscal years in which all non-cap-exempt H-1B visas were awarded through lotteries. We find that the H-1B lottery win rate positively predicts the likelihood of receiving external financing during the next three years. ${ }^{3}$ This result is robust to controlling for firm characteristics, such as the amount raised in prior funding rounds, the number of $\mathrm{H}-1 \mathrm{~B}$ applications, and the average salary of the H-1B petitions. We further control for industry-cityyear fixed effects, ensuring that our results are relevant for comparable firms. The economic magnitude of the result is large. For example, a one standard deviation increase in the win rate is associated with a 4.3 percentage point increase in the likelihood that the firm receives subsequent external funding (a 10\% increase relative to the baseline funding rate). Strikingly, the magnitude of this effect is little changed by the inclusion of controls or various fixed effects, indicating that

\footnotetext{
${ }^{3}$ By “external financing” we simply mean external, private equity investment obtained by the firm. A vast majority of this is funding by venture capitalists. We also examine how H-1B lottery outcomes are related to subsequent funding from high-reputation venture capital firms.
} 
the outcome of $\mathrm{H}-1 \mathrm{~B}$ visa lotteries is indeed random and uncorrelated with observable firm characteristics.

The key identification assumption for our results is that a company's H-1B lottery win rate is exogenous to the quality of the firm and its prospects. This assumption appears reasonable, as the U.S. Citizenship and immigration Services (USCIS) states that it uses “a computer-generated random selection process" to select $\mathrm{H}-1 \mathrm{~B}$ visa applications in the years included in our sample. Nevertheless, as a test of the key identifying assumption, we regress the H-1B lottery win rate on firm and application characteristics. Consistent with H-1B visa lottery outcomes being random, we fail to find that lottery outcomes are significantly related to firm and application characteristics.

Because exit through IPOs or acquisitions is commonly used as a measure of success for start-up firms (e.g., Hochberg, Ljungqvist, and Lu, 2007; Sørensen, 2007; Kerr, Lerner, and Schoar, 2014; Bernstein, Giroud, and Townsend, 2016), we examine the effect of H-1B visa lottery outcomes on the probability of a successful exit. We find that firms with higher win rates are significantly more likely to have a successful exit. The economic magnitude of this result is large. For example, a one standard deviation increase in the win rate is associated with a 2.9 percentage point increase in the probability of a successful exit over a five-year period following the lottery, representing a $20 \%$ increase relative to the baseline exit rate.

Because going public is the most desirable outcome for start-up firms (e.g., Brau, Francis, and Kohers, 2003), we further examine the effect of H-1B visa lottery outcomes on the probability of having an IPO. We find that firms with higher win rates in the H-1B lottery are significantly more likely to go public. For example, a one standard deviation increase in the win 
rate is associated with a 1.5 percentage point increase in the probability of an IPO, representing a 23\% increase relative to the baseline IPO rate over a five-year window following the lottery. We next examine one possible mechanism through which high-skill foreign workers could affect the outcomes of start-up firms - through their contribution to innovation. To test this, we match firms in our sample with patent data from the United States Patent and Trademark Office (USPTO) and construct four measures of innovation performance: the number of patents, the adjusted number of patents, the number of adjusted citations, and the average number of adjusted citations per patent. We find that the win rate in the H-1B visa lottery has a significant positive effect on innovation outcomes across the four measures. The economic magnitudes of the results are nontrivial. For example, a one standard deviation increase in the win rate is associated with a $4.8 \%$ increase in the number of patents and a $4.0 \%$ in the number of adjusted patent citations. These results suggest that highly skilled foreign workers contribute to the innovation success of start-up firms.

Our paper contributes to the literature on the economic impacts of high-skilled foreign workers. Kerr and Lincoln (2010) show that increases in the H-1B admission cap (at the national level) lead to increased patenting by Indians and Chinese in cities and firms that are more dependent on the $\mathrm{H}-1 \mathrm{~B}$ program. However, using $\mathrm{H}-1 \mathrm{~B}$ visa lotteries in two fiscal years during which only a small fraction of the visas are allocated through lotteries, Doran, Gelber, and Isen (2016) find that winning H-1B visas has insignificant or modest effects on firms' patenting, and that the H-1B workers crowd out domestic workers. Peri, Shih, and Sparber (2015) show that negative shocks in the supply of $\mathrm{H}-1 \mathrm{~B}$ visas induced by the lotteries at the city level lead to reduced employment growth in both foreign and domestic-born workers, suggesting a complementarity between the two. Our paper complements the existing studies by using the 
variation in the supply of $\mathrm{H}-1 \mathrm{~B}$ visas at the firm level for four years when all $\mathrm{H}-1 \mathrm{~B}$ visas are allocated through lotteries and focusing on the funding and patenting outcomes of start-up firms.

Our paper also complements studies such as Kerr, Lerner, and Schoar (2014) and Howell (2017) that provide evidence of the causal effects of angel financing and government R\&D subsidies, respectively, on the outcomes of start-up firms. Both papers identify causal effects by exploiting internal rankings of agents who provide funding to start-ups. As Kerr, Lerner, and Schoar (2014) highlight, identifying causal determinants of entrepreneurial success has proven a challenge for the literature. Our paper highlights, through exogenous random assignment, the importance of high-skilled labor to start-up firm outcomes, including economically large effects on the patenting outcomes, the likelihood of obtaining subsequent financing, and having an IPO.

The rest of the paper is organized as follows. Section 1 discusses the background on $\mathrm{H}$ 1B visa lotteries. Section 2 describes our data sources and reports summary statistics. Section 3 evaluates the validity of our win rate variable. Section 4 presents our main empirical results. Section 5 examines the dynamics of the effects of H-1B lottery wins over time. Section 6 presents results for patenting outcomes, and Section 7 concludes.

\section{Background on H-1B Visas}

The purpose of the H-1B visa is to allow U.S. employers to hire skilled foreign workers in specialty occupations "that requires (a) theoretical and practical application of a body of highly specialized knowledge and (b) attainment of a bachelor's or higher degree in the specific specialty (or its equivalent) as a minimum for entry into the occupation in the United States”

(U.S.C. $\oint 1184(\mathrm{i})(1))$. An H-1B visa permits the holder to work in the U.S. for three years, renewable once for an additional three years (maximum total of six years), and the employer can sponsor the H-1B visa holder for permanent residency. 
For an individual to receive an $\mathrm{H}-1 \mathrm{~B}$ visa they must have an offer of employment from a U.S. firm. The firm must file a Labor Condition Application (LCA) with the Department of Labor, stating that the employment offer complies with the requirements of the H-1B visa program. ${ }^{4}$ The LCA includes information about the firm, such as its name, address, and industry. The LCA also includes information about the position, such as the salary and starting date. If the Department of Labor certifies the LCA, the potential employee may apply for an H-1B visa by submitting an I-129 petition to U.S. Citizenship and Immigration Services (USCIS).

The number of H-1B visas available to for-profit firms is capped in each federal government fiscal year (beginning on October 1 and ending September 30 of the subsequent year). During our sample period, the quota of available new H-1B visas was capped at 65,000 per fiscal year (the regular cap), with an additional quota of 20,000 H-1B visas available for individuals who hold a master's degree or Ph.D. from an eligible and accredited U.S. based university (the master's cap). The quotas apply only for new H-1B applications (not renewals or transfers between employers) made by for-profit firms (e.g., not-for-profit universities are not subject to the cap).

LCAs can be filed up to six months before the employment starting date and typically take about a week to be approved. The USCIS begins processing applications on April 1 for positions beginning in October of that year, and continues to process applications until that year's quota has been filled. Figure 1 illustrates the timeline of the application process. Because of the sequential approval process, firms frequently "pre-date” LCA applications by filing LCAs

\footnotetext{
${ }^{4}$ In addition to ensuring that the H-1B applicant would work in a specialty occupation, the employer must attest that: the applicant would be paid at least the "prevailing wage" for similarly positions in the geographic area; the applicant will not displace or negatively affect similarly employed U.S. workers; and the firm is not involved in a strike, lockout, or work stoppage. Further, the firm must also post the LCA at the firm's place of business in at least two clearly visible locations. See https://www.foreignlaborcert.doleta.gov/faqsanswers.cfm\#h1b_programs.
} 
prior to April 1, giving a start date that is 180 days in the future. For example, an LCA filed on March 1, 2014 for new employment would specify a start date of August 28, 2014 (although the effective start date is the start of the government fiscal year, i.e., October 1, 2014) and an end date of August 27, 2017. Pre-dated and approved LCAs can then be used to file I-129 petitions immediately at the beginning of April. The cost of pre-dating is that the firm loses one or two months at the end of the desired work period as LCAs are valid for a maximum of three years. See Peri, Shih, and Sparber (2015) for further discussion of pre-dating.

For fiscal years 2008, 2009, and each fiscal year beginning from 2014 onward, all new H-1B visas were allocated by USCIS lotteries using “a computer-generated random selection process," because the quota of available $\mathrm{H}-1 \mathrm{~B}$ visas was oversubscribed within the filing period (i.e., the first five business days of the April preceding the fiscal year). ${ }^{5}$ In other years, because the cap was reached after the filing period, the majority of the visas were granted on a firstcome-first-served basis. In each year when the cap was reached within the filing period, USCIS first conducted a lottery to assign the 20,000 H-1B visas available under the master's cap. After this lottery, the unselected applicants from the master's cap lottery are pooled with the applicants who are not eligible for the master's cap, and a second lottery is conducted to assign the remaining 65,000 H-1B visas. Thus, individuals eligible for the master's cap pool have a higher probability of receiving an $\mathrm{H}-1 \mathrm{~B}$ visa relative to ineligible applicants. Applications that are not selected in either lottery are then returned unopened, and USCIS does not retain records of the unselected applicants (see Clemens, 2013; Peri, Shih, and Sparber, 2015).

\footnotetext{
${ }^{5}$ For example, see https://www.uscis.gov/news/alerts/uscis-completes-h-1b-cap-random-selection-process-fy-2019.
} 


\section{Data and Variables}

Our study combines data from multiple sources. We obtain data on H-1B visa applications and approvals from the Department of Labor and U.S. Citizenship and Immigration Services (USCIS). We obtain data on a set of private start-up companies from Crunchbase.

Finally, we obtain data on patents from the public use PatentsView data files, made available by the United States Patent and Trademark Office (USPTO).

To construct our sample of firm-fiscal year observations, we begin with the set of Crunchbase firms that meet the following criteria: (1) the firm is a private firm as of the April 1 preceding the federal government fiscal year, (2) it has completed at least one round of external financing, and (3) the dollar amount of the prior external financing is available. Using firm names and addresses, we match the Crunchbase firms to the $\mathrm{H}-1 \mathrm{~B}$ data and retain the firms that applied for at least one H-1B visa for fiscal years 2008, 2009, 2014, and 2015. There are 1,866 unique firms meeting these criteria and 2,570 firm-year observations. Consistent with prior studies using the Crunchbase data, such as Wang (2017), the firms in our sample are concentrated in a few states: $49 \%$ in California, 10\% in Massachusetts, and 9\% in New York.

\subsection{H-1B Visa Data}

We obtain data on approved H-1B applications from USCIS through a Freedom of Information Act (FOIA) request. Our analyses focus on fiscal years 2008, 2009, 2014, and 2015, because in these fiscal years all new $\mathrm{H}-1 \mathrm{~B}$ visas were granted through lotteries. In contrast, for fiscal years 2010-2013 there was less demand for new H-1B visas and most applications were not subject to a lottery. The data provide the number of new H-1B petitions (i.e., petitions for initial employment) that are approved by USCIS for each employer in each government fiscal 
year. Since the USCIS does not retain records of the unselected H-1B petitions (see Clemens, 2013), we obtain information on H-1B applications from an alternative data source.

We obtain data on firms' Labor Condition Applications (LCA) from the Department of Labor. ${ }^{6}$ The data provide detailed information for each prospective foreign worker, including job information such as salary and the intended starting and ending dates; employer information such the firm's name, address, and NAICS code; and the status of the application (i.e., whether it is certified, withdrawn, or denied). We use the number of certified (and not withdrawn) LCAs for $\mathrm{H}-1 \mathrm{~B}$ visas filed by a firm in February and March with a start date that is five to six months in the future as a proxy for the firm's demand for new H-1B workers in the upcoming fiscal year. ${ }^{7}$ Table 1 shows that the average firm-year in the sample applies for $2.5 \mathrm{H}-1 \mathrm{~B}$ visas. Figure 2 shows that $58 \%$ of the sample applies for a single visa and only $6.6 \%$ apply for more than five.

We create our key explanatory variable, Win Rate, defined as the number of approved new $\mathrm{H}-1 \mathrm{~B}$ visas divided by the number of applications. Table 1 shows the average Win Rate for firms in the sample is 55\%. Based on USCIS press releases, the overall $\mathrm{H}-1 \mathrm{~B}$ lottery win rate for the four years in our sample is approximately $56.6 \%{ }^{8}{ }^{8}$ Thus, the Win Rate in our sample of startup firms is comparable to that in the full sample. Panel A of Figure 3 shows a histogram of Win Rate. As would be expected from the fact that most firms in our sample apply for only a single visa, the observations are clustered at zero and one. The distribution of Win Rate highlights an important advantage of focusing on a sample of small firms - with few applications there is a large dispersion in Win Rate. In contrast, for firms with a large number of applications their Win Rate will tend to the sample average by the law of large numbers.

\footnotetext{
${ }^{6}$ The data are available at https://www.foreignlaborcert.doleta.gov/performancedata.cfm.

${ }^{7}$ See Section 3.2 for a detailed discussion of our choice of the screens.

${ }^{8}$ See https://www.uscis.gov/archive. The USCIS reports approximate application numbers rounded to the nearest thousand.
} 
In the LCA filing, companies are required to state the salary offered to the $\mathrm{H}-1 \mathrm{~B}$ visa applicant. For companies that file multiple LCAs in a given fiscal year, we take the average of the reported salaries. As Table 1 shows, the average (median) salary offered to the H-1B applicants is $\$ 85,100(\$ 80,000)$.

\subsection{Crunchbase Data}

We obtain data on start-up firms from Crunchbase, a crowd-sourced database that tracks events related to start-up companies, especially those in high-tech sectors. ${ }^{9}$ As of April 2019, the dataset covers over 233,000 firms and more than 366,000 events (including private funding rounds, IPOs, and acquisitions). For each start-up firm, Crunchbase provides the name, address, and industry of the firm, as well as detailed information on the events (e.g., the date, type, and amount of a funding round, and the date of an IPO or acquisition). To ensure the Crunchbase data for the firm is sufficiently detailed and to avoid introducing a look-ahead bias, we limit our sample to firms that are already in the Crunchbase data at the time of the lottery (i.e., those that have completed at least one prior round of external financing and report the dollar amount of prior external financing). Because our focus is on start-ups, we exclude firms that have already gone public. We then match firms in the Crunchbase data with employers in our H-1B data using names and addresses.

A number of recent studies examine the Crunchbase data and its reliability. Dalle, den Besten, and Menon (2017) compare the Crunchbase database with the OECD Entrepreneurship Financing Database and with the VentureXpert database, and conclude that “...the coverage is very comprehensive, especially for start-ups located in the United States.” Ling (2016) manually

\footnotetext{
${ }^{9}$ Crunchbase was founded in 2005 and the data before 2005 are backfilled (see Wang, 2017). Since our sample starts from federal government fiscal year 2008, this backfill issue is unlikely to bias our results.
} 
compares transaction amounts for a subsample of Crunchbase firms with data from business publications and VentureXpert, and concludes that the Crunchbase data are accurate. Similarly, Block, Fisch, Hahn, and Sandner (2015) and Wang (2017) argue that Crunchbase provides the most comprehensive coverage for early-stage innovative firms.

From the Crunchbase data we create several control variables. The summary statistics in Table 1 show that firms in the sample have completed an average of 2.8 prior financing rounds, have received an average of $\$ 40.1$ million in prior external financing, had their first financing round 56.0 months ago, and the most recent round 26.3 months ago. All control variables are measured as of the March 31 prior to the H-1B visa lottery (which is held in April), and thus are measured before the uncertainty related to the $\mathrm{H}-1 \mathrm{~B}$ visa lottery is resolved. Figure 1 provides a timeline of the $\mathrm{H}-1 \mathrm{~B}$ visa process and the timing of our variables.

From the Crunchbase data, we create several firm-level outcome variables. These variables are based on events that occur during the three year period beginning in October of the year of the H-1B lottery (i.e., the three year period during which the H-1B visas awarded in the lottery would grant the recipient the right to work in the U.S.). The first variable, Funded, is an indicator variable for firms that receive additional external financing. Numerous prior studies use external financing as a signal of a firm's success (e.g., Hochberg, Ljungqvist, and Lu, 2007; Kerr, Lerner, and Schoar, 2014; Howell, 2017). Table 1 shows that $44.7 \%$ of the firms in our sample receive external funding in the three years following the lottery. Panel B of Figure 3 shows Funded for different levels of Win Rate (conditional on having at least 100 observations for that level of Win Rate). The figure shows that firms with a Win Rate of zero receive subsequent funding $40.6 \%$ of the time, while firms with a Win Rate of $100 \%$ receive subsequent funding $48.9 \%$ of the time. 
Prior studies show that venture capitalists (VCs) vary in their quality, and that more reputable VCs improve firm outcomes. ${ }^{10}$ Following Atanasov, Ivanov, and Litvak (2012) and Puri and Zarutskie (2012), we construct three measures of VC reputation: VC age defined as the number of years since the first deal the VC participated in, the number of deals that the VC has invested in, and the number of the VC's portfolio companies that went public. For each measure, we define high-reputation VC firms as those that rank in the top decile of the distribution of that measure in the given year. We also create a composite VC reputation measure that indicates VC firms that rank in the top decile for any one of the three measures. Using the composite VC reputation measures we create the variable Funded High Reputation $V C$, which is an indicator for firms that receive external funding from a high reputation VC firm in the three year post-lottery period (note that the variable Funded High Reputation VC is thus a subset of the variable Funded). The average Funded High Reputation VC is $24.3 \%$ in our sample.

From the Crunchbase data, we create two additional measures of firm outcomes. IPO is an indicator for firms that have an initial public offering during the post-lottery period. Successful Exit is an indicator for firms that either have an IPO or are acquired for at least \$25 million (in inflation adjusted 2008 dollars). ${ }^{11}$ We follow Bernstein, Giroud, and Townsend (2016) and include only acquisitions above this threshold as, unlike IPOs, acquisitions do not necessarily indicate a successful exit. Indeed, Metrick and Yasuda (2011) note that many acquisitions result in a loss for investors. The means of IPO and Successful Exit in our sample are $4.3 \%$ and $9.5 \%$, respectively.

\footnotetext{
${ }^{10}$ See Gompers (1996), Sørensen (2007), Bottazzi, Da Rin, and Hellman (2008), and Zarutskie (2010).

${ }^{11}$ For observations where Crunchbase does not report the acquisition amount, we search the SDC Platinum database. If we are unable to find the acquisition amount we do not include the acquisition in the Successful Exit measure, as Metrick and Yasuda (2011, pg. 127) note that these often “indicate a going-out-of-business sale.”
} 
Internet Appendix Table 1 compares our sample of Crunchbase firms that file LCAs with Crunchbase firms that do not file LCAs. Consistent with the intuition that firms that actively seek high-skill foreign labor have relatively good prospects, the LCA filers have received significantly more prior funding. The LCA filers are also significantly more likely to receive subsequent external funding and to have an IPO, so they are better both ex ante and ex post at least in terms of financing outcomes. Accordingly, in our empirical tests we limit the sample to include only Crunchbase firms that file for LCAs, as this avoids sample selection biases due to the higher quality of LCA filing firms. We are not comparing a firm that hires high-skill immigrant labor with a firm that does not (these firms likely have very different growth prospects). Instead, we are comparing two firms that both want to hire high-skill labor, with chance (i.e., the H-1B visa lotteries) determining which firm is allowed to hire the high-skill worker.

\subsection{Patent Data}

A large number of prior studies use the number of patents and patent citations as measures of innovative success ${ }^{12}$ and numerous studies show that these variables are correlated with the value of innovation. ${ }^{13}$ To examine innovation in our sample, we obtain patent data from the USPTO data tables provided through PatentsView, ${ }^{14}$ and match Crunchbase firms to the patent assignee identifiers in the PatentsView data using firm names and locations. The PatentsView dataset includes information on all patents granted between January 1976 and

\footnotetext{
12 Lerner and Seru (2017, Appendix 1) list 68 papers published in the top three finance journals from 2005-2017 that use patent data.

${ }^{13}$ For example, see Pakes (1985), Griliches (1990), Trajtenberg (1990), Austin (1993), Hall, Jaffe, Trajtenberg (2005), and Kogan, Papanikolaou, Seru, and Stoffman (2017).

14 The PatentsView data tables are available at http://www.patentsview.org/download/. In this paper, we use the data files as of the May 28, 2018 update. The advantage of the PatentsView database is that it is regularly updated. In contrast, other patent databases, such as the NBER patent database, do not include data for recent years.
} 
December 2017, including information about technology classes and citations. For each approved patent, the dataset provides both the application date and the approval date.

Using the PatentsView data, we create several dependent variables that measure the firms' innovative output. Each of these variables is based on approved patents that the firm applied for during the three year period that the H-1B visa applied for would be valid. ${ }^{15}$ In the regressions, we control for lagged values of the patenting activity during the three year period before the H-1B visa lottery. ${ }^{16}$

Following the literature, we adjust both the number of patents and the number of citations based on the year of application and technology category. Hall, Jaffe, and Trajtenberg (2001, 2005) argue that un-adjusted patent variables are subject to truncation bias and are not directly comparable across time or technology categories. Truncation bias in the number of patents occurs because we observe only approved patent applications. Patent approval takes an average of two years but can take considerably longer (e.g., see Dass, Nanda, and Xiao, 2017; Lerner and Seru, 2017). As a result, recent patent applications that are still undergoing the approval process are unobservable. Truncation bias in the number of citations occurs because patent citations accumulate over time; thus, citation counts are not comparable across patents of different vintages. Further, patent counts and citations are not directly comparable across different technological categories, because of differences in patenting rates, approval rates, and typical citation life-cycles (see Dass, Nanda, and Xiao, 2017; Lerner and Seru, 2017).

\footnotetext{
${ }^{15}$ For example, for federal government fiscal year 2008 our dependent variable would include patents applied for during the period October 1, 2007 thought September 30, 2010, because this is the period during which the H-1B visa holder would be allowed to work for the firm.

${ }^{16}$ For example, for federal government fiscal year 2008 the USCIS began accepting applications on April 1, 2007. Accordingly, the control variables are based on approved patents applied for during the period April 1, 2004 through March 31, 2007.
} 
To adjust for these problems, we follow Hall, Jaffe, and Trajtenberg (2001, 2005), Lerner, Sørensen, and Strömberg (2011), Bena and Li (2014), Seru (2014), and Chang, Fu, Low, and Zhang (2015) and adjust both the number of patents and citations per patent. We adjust the number of patents as follows. First, for each technology category and year, we compute the average number of patents per firm (conditional on the firm having at least one patent in the category-year). Second, we scale each patent by the average found in the first step. Third, we sum the scaled number of patents across all (approved) patents applied for by the firm in that year. Similarly, we adjust the citations per patent by first computing the average number of citations per patent in a given technology class-year. Second, we scale the citations per patent using this average. Third, we sum the scaled citations per patent across all (approved) patents applied for by the firm in that year. ${ }^{17}$

The summary statistics in Table 1 show that $32.2 \%$ of the firm-years in our sample have at least one patent in the three-year period following inclusion in our sample and the average number of patents is 5.4. Patent numbers are highly skewed, however, with less than $1 \%$ of the firms responsible for half of the approved patents.

\section{Evaluating the Validity of the Win Rate Variable}

The key identification assumption for this paper is that the Win Rate captures exogenous variation in firms’ access to skilled foreign labor. Given that $\mathrm{H}-1 \mathrm{~B}$ visas are assigned by computer generated pseudo-random numbers during our sample years, this assumption appears reasonable. However, there are two issues that could affect the validity of the Win Rate. First, H-1B applications that are eligible for the master's cap have a higher probability of selection.

\footnotetext{
${ }^{17}$ Dass, Nanda, and Xiao (2017) and Lerner and Seru (2017) show that these adjustment methods are less effective towards the end of any given sample period (when truncation issues are more severe). Thus, we report results for patenting using both the full sample and using only data from the H-1B lotteries for the 2008 and 2009 fiscal years.
} 
Second, because we impute H-1B applications for new employment from LCA filings, there is some measurement error in the denominator of Win Rate. In this section, we address these two issues and provide empirical support for the validity of the Win Rate variable.

\subsection{H-1B Master's Cap}

As discussed in Section 1, there are two separate pools for the H-1B lottery. First, applicants with an approved U.S. graduate degree are entered into a lottery for the 20,000 “master’s cap” visas. Second, the non-selected master’s cap applicants are pooled with the nonmaster's cap applicants in a second lottery for the remaining 65,000 visas. Thus, H-1B applicants eligible for the master's cap pool have a higher probability of winning. Unfortunately, neither the LCA data nor the USCIS FOIA data indicate whether an applicant was entered in the master's cap pool. We can, however, examine how applicant education correlates with variables in the LCA data using the education information that is included in the prevailing wage determination (PWD) data files provided by the Department of Labor (available for the 2014 and 2015 fiscal years). As part of the LCA process, firms must certify that the salary offered to the foreign worker will be at least as high as the "prevailing wage" offered to domestic workers with similar qualifications in the same occupational category. The firm must support its claim with reference to a prevailing wage determination source, such as the PWD program. ${ }^{18}$

We examine the PWD data ${ }^{19}$ and find that the baseline fixed effects we include in our regressions absorb much of the variation in applicant education. Specifically, industry-city-year

\footnotetext{
${ }^{18}$ Firms are not required to file a PWD as part of the LCA process and a majority of firms do not use the PWD system but instead rely on alternative sources such as the Occupational Employment Statistics database. Thus, we are not able to match most of our LCA filings to a PWD filing.

${ }^{19}$ The PWD data sample we use includes only filings related to H-1B visas. We exclude filings that are cap-exempt, i.e., those by universities and other educational institutions, hospitals, clinics, medical institutions, and research instituions, and those for medical doctors and dentists.
} 
fixed effects explain $73 \%$ of the variation in whether an applicant has a graduate degree. In the subsequent section, we show that the inclusion of these fixed effects has little effect on the coefficient on Win Rate. Given that these fixed effects directly absorb most of the variation in applicant education, applicant education seems unlikely to bias our findings for Win Rate.

\subsection{The Imputation of Applications for New Employment from LCA Filings}

We construct the Win Rate variable as the number of newly approved H-1B visas divided by the number of applications for new employment imputed from LCA filings. During our sample period, the LCA data released by the U.S. Department of Labor do not state whether an LCA is for new employment. However, beginning in 2017 the LCA data started to include information on whether an LCA petition is for new employment. We use the 2017 data to perform a check on the choice of the window we use to identify LCAs for new employment in our sample years. We retrieve all certified LCAs for H-1B visas submitted in fiscal year 2017.

To focus on firms that are similar to those in our main sample, we manually match employers in the 2017 LCA dataset with firms in Crunchbase using firm name and address. We require that firms in Crunchbase meet the following criteria: (1) it is a private firm as of April 1, 2017, (2) it has completed at least one round of external financing, and (3) the dollar amount of the prior external financing is available. We are able to match 1,018 firms in Crunchbase with employers in the 2017 LCA data.

We compute the false negative rate and false positive rate for LCAs submitted by the matched Crunchbase firms in a given month from December 2016 through April 2017. A false negative is defined as an LCA for new employment that does not have a start date that is five to six months in the future. A false positive is defined as an LCA with a start date five to six months in the future that is not for new employment. 
Internet Appendix Table 2 shows that the vast majority of the LCAs for new employment are submitted in February and March. Also, the vast majority of LCAs filed in February and March are for new employment (roughly 80\%), while filings for new employment constitute a small fraction of LCAs in other months. Only about $1-2 \%$ of the workers filing for new employment in February and March do not have a start date that is five to six months in the future, suggesting that the requirement on the start date does a remarkably good job of identifying petitions for new employment in these two months. Similarly, February and March have the lowest false positive rates (5.9\% and $10.5 \%$ respectively). In contrast, petitions submitted in January have a false positive rate of 35\%, and those submitted in December and April have a false positive rate greater than $80 \%$. These numbers suggest that our imputation algorithm provides reasonably precise estimates of the number of $\mathrm{H}-1 \mathrm{~B}$ applications for new employment.

\subsection{Win Rate is Not Predictable}

If the H-1B lottery Win Rate variable captures exogenous variation in firms' access to high skill foreign workers, then Win Rate should not be predictable using lagged firm characteristics or information about the applicants. For example, Clemens (2013) tests whether H-1B visa lottery outcomes are predictable based on applicant age, education, and work experience, and fails to find any significant relations, and concludes this is "strong evidence of true natural randomization.” Following this logic, we regress Win Rate on the baseline set of control variables, all of which are measured prior to the H-1B lottery.

The results are shown in Table 2. In both columns, the control variables include $\log$ (number of rounds of financing), $\log$ ( $\$$ amount raised previously), $\log$ (months since first round), $\log$ (months since last round), $\log ($ number of $\mathrm{H}-1 \mathrm{~B}$ applications), $\log$ (\$ salary for $\mathrm{H}-1 \mathrm{~B}$ 
positions), and $\log (1+$ number of prior patents $)$. Column (1) includes government fiscal-year fixed effects. Column (2) includes industry-city-year fixed effects.

In column (1) a single control variable is significant and in column (2) none of the control variables are significant. For both columns, the overall model that contains several measures of firm quality prior to the lottery is not statistically significant as shown by the model F-statistic (i.e., the seven control variables are jointly not statistically different from zero). The insignificance of the coefficient estimates and the insignificant model F-statistics are consistent with the claim that the H-1B lottery Win Rate provides exogenous variation in access to highskilled labor.

\section{H-1B Visa Lottery Outcomes and Additional Financing}

\subsection{H-1B Visa Lottery Outcomes and External Financing}

We run linear regressions to examine the effect of winning $\mathrm{H}-1 \mathrm{~B}$ visa lotteries on the likelihood of receiving additional external funding. ${ }^{20}$ The dependent variable in Table 3 is Funded, an indicator variable equal to 100 if the company receives additional external funding during the three-year period beginning October 1 following the H-1B visa lottery and zero otherwise. In column (1), the specification does not include any controls or fixed effects. In column (2), the specification includes the following controls: log(number of rounds of financing), $\log (\$$ amount raised previously), $\log ($ months since first round), $\log ($ months since last round), $\log ($ number of $\mathrm{H}-1 \mathrm{~B}$ applications), $\log (\$$ salary for $\mathrm{H}-1 \mathrm{~B}$ position $)$, and $\log (1+$ number of prior patents). Column (2) also includes industry-city-year fixed effects. Both columns report $t$-statistics based on standard errors clustered by firm.

\footnotetext{
${ }^{20}$ For robustness, Internet Appendix Table 4 reports results estimated using logit and conditional logit models.
} 
In both specifications, the coefficient estimate on Win Rate is positive and significant. ${ }^{21}$ Firms that win in the H-1B lottery are more likely to receive additional funding than firms that lose. Further, the economic magnitude of the result is large. For example, the coefficient in column (2) implies that a one standard deviation increase in Win Rate is associated with a 4.3 percentage point increase in the likelihood that the firm is funded (a 10\% increase relative to the baseline funding rate).

The magnitude of the coefficient on Win Rate represents both direct and indirect effects of winning the right to employ a high-skill foreign worker. For example, besides the direct contribution of the high-skill worker to the firm, the worker may have positive externalities on the firm's workforce (Bernstein, Diamond, McQuade, and Pousada, 2018). Further, a positive experience with one $\mathrm{H}-1 \mathrm{~B}$ worker may encourage the firm to apply for more $\mathrm{H}-1 \mathrm{~B}$ visas in future years.

The coefficient estimates are stable across the specifications. In column (1), the regression does not include any controls whatsoever. In this regression, the result shows how variation in Win Rate affects the likelihood of receiving additional funding among all firms and years in the sample. In column (2), the regression includes control variables and industry-cityyear fixed effects. In this regression, the comparison group is limited to other firms that operate in the same industry and are located in the same city during the same year. Further, this regression controls for many of the firms' characteristics and its H-1B application profile. These fixed effects and controls explain a large portion of the variation in Funded; the $R^{2}$ increases from 0.005 to 0.558 . The coefficient on Win Rate, however, is not significantly different

\footnotetext{
${ }^{21}$ Throughout the paper, the Win Rate variable is calculated using LCA applications filed during February and March. For robustness, we repeat the tests in Table 3 using LCAs filed during January-March and December-March as alternative windows. The results presented in Internet Appendix Table 3 show that using these alternative windows produce essentially the same results as in the baseline specification.
} 
between the two columns $(p$-value $=0.46)$. The stability of the coefficient estimate across specifications is consistent with the argument that Win Rate captures random lottery outcomes and is essentially uncorrelated with observable characteristics of the firms.

Oster (2019) formalizes the insights of Altonji, Elder, and Taber (2005) and develops a method for evaluating omitted variable bias, based on comparing coefficient and $R^{2}$ changes after including control variables. Her method shows it is possible to compute an identified set for the coefficients, subject to the assumption that selection on observables is proportional to selection on unobservables. Formally, the identified set is $\left[\tilde{\beta}, \tilde{\beta}-[\dot{\beta}-\tilde{\beta}]\left(\frac{R_{M a x}^{2}-\tilde{R}^{2}}{\tilde{R}^{2}-\dot{R}^{2}}\right)\right]$, where $\tilde{\beta}$ is the coefficient estimate in the specification with the full set of controls, i.e., column (2), and $\widetilde{R}^{2}$ is the corresponding R-squared, $\dot{\beta}$ and $\dot{R}^{2}$ are the coefficient estimate and R-squared from the specification with no controls, i.e., column (1), and $R_{\operatorname{Max}}^{2}$ is the unobservable maximum Rsquared possible in a model that contained all remaining unobservable sources of variation. We use $R_{\text {Max }}^{2}=1$ as this represents the clear upper boundary. Using this method, we find the identified set for the coefficient on Win Rate is [9.85, 11.22]. This set does not include zero and encompasses a fairly tight range of magnitudes, suggesting that it is statistically unlikely that unobserved variables bias the results.

\subsection{H-1B Visa Lottery Outcomes and Financing by High-Reputation VCs}

Prior studies show that high-reputation VCs select better investments and improve firm outcomes (e.g., Sørensen, 2007). Winning H-1B visa lotteries might enable start-up firms to secure funding from more reputable VCs. Accordingly, we construct several proxies for VC reputation following Atanasov, Ivanov, and Litvak (2012) and Puri and Zarutskie (2012). The first is VC Age, defined as the number of years since the first deal the VC participated in. The second is VC Number of Deals, defined as the number of deals that a VC has invested in. The 
third is VC Number of IPOs, defined as the number of the VC's portfolio companies that went public. For each measure, we define high-reputation VCs as those ranking in the top decile of the distribution of that measure in the given year. We also construct VC Composite, which identifies VCs that rank in the top decile of any one of the three measures.

Table 4 regresses indicators for whether the firm obtains funding from a high-reputation VC over the subsequent three years on the Win Rate, firm controls (including an additional control for whether the firm had previously received funding from a high-reputation VC), and industry-city-year fixed effects. This dependent variable is a subset of the Funded variable used in Table 3. In all specifications, the coefficient estimate on Win Rate is positive and significant. Firms with a higher win rate in the H-1B lottery are more likely to receive funding from highreputation VCs. The economic magnitude of the result is large as well. For example, the coefficient in column (4) implies that a one standard deviation increase in Win Rate is associated with a 3.6 percentage point increase in the likelihood the firm is funded by a high-reputation VC (a 15\% increase relative to the baseline probability). These results provide strong support for the idea that winning $\mathrm{H}-1 \mathrm{~B}$ visa lotteries enables firms to obtain funding from high-reputation VCs and potentially benefit from the expertise, network, and resources of these VCs.

\section{The Dynamics of the Effect of H-1B Visa Lottery Outcomes}

\subsection{External Funding}

In this section, we examine how $\mathrm{H}-1 \mathrm{~B}$ lottery results are related to external funding outcomes over time. Following the lottery held in early April, H-1B visa recipients can begin employment at the beginning of October. The H-1B visa is valid for three years and renewable for up to three additional years. We would expect any effects from the H-1B visa holder to accumulate over the life of the visa. Accordingly, in Panel A of Table 5 we examine the relation 
between Win Rate and external funding while progressively increasing the window in which we examine funding outcomes. In column (1), Funded is measured over the 12-month period beginning once the H-1B visa becomes valid. In columns (2) and (3), Funded is measured, respectively, over the 36 - and 60 -month periods beginning once the H-1B visa becomes valid. ${ }^{22}$ Thus, these variables are cumulative (i.e., funding received during the first 12 months is also received during the first 36 and 60 months). ${ }^{23}$

The results in Panel A of Table 5 show that the economic effect of Win Rate increases over time; the coefficient of Win Rate on Funding doubles in magnitude between one and three years (then is essentially unchanged as the horizon increases from three to five years). This pattern is intuitive: the effect of employing an $\mathrm{H}-1 \mathrm{~B}$ visa worker on external funding does not all happen immediately, but instead takes about three years to fully materialize.

\subsection{Successful Exits and Initial Public Offerings}

In this section, we consider two alternative firm-level outcome variables. IPO is an indicator variable for firms that have an initial public offering. Successful Exit is an indicator variable for firms that either have an IPO or are acquired for at least \$25 million (in inflation adjusted 2008 dollars). Prior studies have used IPO and exit as measures of firm success (e.g., Hochberg, Ljungqvist, and Lu, 2007; Sørensen, 2007; Kerr, Lerner, and Schoar, 2014; Bernstein, Giroud, and Townsend, 2016). For both dependent variables, we show the results when the dependent variable is measured over the 12-, 36-, and 60-month periods after the $\mathrm{H}-1 \mathrm{~B}$ visa

\footnotetext{
${ }^{22}$ For government fiscal year 2015 observations, post-lottery data is available on funding, acquisition, and IPO outcomes from October 2014 through April 2019. So the five-year outcome window is actually 55 months for 2015 observations.

${ }^{23}$ Note that for Funded, there can be multiple positive events across years. For example, of firms that receive external funding in the first year, $36 \%$ also receive funding in the second year and $29 \%$ also receive funding in the third year.
} 
becomes valid (e.g., the 12-month period runs from October of the lottery year through September of the next year).

In Panel B of Table 5, the dependent variable is Successful Exit. The coefficient on Win Rate is significant for one- and three-year horizons at the $10 \%$ level and significant at the $1 \%$ level over a five-year horizon. The economic magnitude of the results is large. For example, the coefficient estimate in column (3) implies that a one standard deviation increase in the Win Rate is associated with a 2.9 percentage point increase in the probability of a successful exit over the next five years (a 20\% increase relative to the baseline Successful Exit rate of 14.9\%).

In Panel C of Table 5, the dependent variable is IPO. The coefficient on Win Rate is marginally significant for the three-year horizon and significant at the $1 \%$ level over a five-year horizon. The economic magnitude of the result for IPOs is also large. For example, the coefficient in column (3) implies that a one standard deviation increase in Win Rate is associated with a 1.5 percentage point increase in the probability of going public (a 23\% increase relative to the baseline IPO likelihood of 6.6\% over the five-year period).

The magnitude of the coefficient on Win Rate on various firm outcomes, particularly long-term outcomes like Successful Exit and IPO, represents the cumulative effect of the H-1B workers through multiple channels. For example, the previous section shows that winning in the H-1B lottery increases the ability of the firm to obtain external financing from high-reputation VCs. The high-reputation VCs could, in turn, have a causal effect on the likelihood of a successful exit. In our regressions, the coefficient on Win Rate includes both the direct effects from the H-1B worker's contributions to the firm as well as indirect effects through other channels such as H-1B workers' positive effect on the likelihood of obtaining external financing and their positive externalities for other workers that also contribute to future firm success. Both 
the direct and indirect effects are caused by the variation in access to high-skilled labor generated by the H-1B lotteries.

Overall, the pattern of results for Funded, Successful Exit, and IPO are quite intuitive. The effects of the H-1B lottery outcomes occur more rapidly for obtaining external financing than they do for having a successful exit or an IPO (which are later stage developments for the start-up). The effect of the H-1B lottery on simply obtaining external financing materializes within 3 years (with little additional effect after that), with the 3- and 5-year effects about double that measured after one year. In contrast, the cumulative effect of winning the H-1B lottery on both Successful Exit and IPO over a five-year horizon is roughly quadruple that measured after only one year and about double that measured at a three-year horizon.

\section{Patenting and Innovation}

High-skilled foreign workers may contribute to start-up firms’ innovation success. Table 6 examines the relation between Win Rate and several variables measuring innovation performance. In all columns, we use our baseline specification that includes firm and applicant controls as well as industry-city-year fixed effects. We also include past patenting activity as a control, ${ }^{24}$ because past patenting activity is a strong predictor of future activity. Panel A reports the results for the full sample. Panel B reports the results using only data for the 2008 and 2009 fiscal years, because the truncation biases discussed in Dass, Nanda, and Xiao (2017) and Lerner and Seru (2017) are less severe with older data.

In column (1), the dependent variable is $\log (1+$ Number of Patents) and in column (2) the dependent variable is $\log (1+$ Adjusted Number of Patents). In both columns there is a

\footnotetext{
${ }^{24}$ Prior patenting activity is measured over the three-year period ending just before the H-1B lottery is held (e.g., for observations on firms participating in the lottery for fiscal year 2009, the control variables are measured over the period from April 1, 2005 through March 31, 2008).
} 
significant and positive relation between Win Rate and the number of patents for both the full sample and for the subsample of fiscal years 2008 and 2009. Further, the economic magnitude of the results is significant. The coefficient estimates in Panel A imply that a one standard deviation increase in the Win Rate increases the number of patents by $4.8 \%$ and the adjusted number of patents by $2.6 \%$.

In column (3), the dependent variable is the logarithm of the adjusted number total patent citations received by patents filed during the three year post $\mathrm{H}-1 \mathrm{~B}$ lottery period. The results show there is a positive and significant relation between Win Rate and the total number of adjusted patent citations for the full sample as well as for the $2008 / 2009$ subsample. The result using the full sample implies that a one standard deviation increase in the Win Rate increases the adjusted number of patent citations by $4.0 \%$, and the magnitude of this relation becomes larger if the sample is restricted to the 2008 and 2009 government fiscal years (when truncation bias is less severe).

The total number of citations for a firm can increase either because the number of patents increases or because the citations per patent increase. To separate these possibilities, in column (4) the dependent variable is the natural logarithm of the average number of adjusted citations per patent. The coefficient on the win rate variable using the full sample is 0.029 and significant at the $10 \%$ level, suggesting that a one standard deviation increase in the Win Rate increases the adjusted citations per patent by $1.3 \%$ (though this effect is not statistically significant in the 2008/2009 subsample). This finding, combined with the results in other columns, suggests that access to $\mathrm{H}-1 \mathrm{~B}$ visa workers increases the total amount of innovative activity with no detrimental effect on the average quality of the innovation (or perhaps a modest increase in the quality of the innovation). 
Our findings for patenting are consistent with those of Kerr and Lincoln (2010) who find a strong positive relation between $\mathrm{H}-1 \mathrm{~B}$ visas and patenting. More generally, our results are consistent with Hunt and Gauthier-Loiselle (2010) and Bernstein, Diamond, McQuade, and Pousada (2018) who find that immigrants are responsible for a disproportionately large fraction of U.S. patents. Our results, however, differ from those of Doran, Gelber, and Isen (2016) who find little relation between firms' H-1B visa approvals and the number of patents. In addition to differences in sample periods, Doran et al. examine the full universe of U.S. firms using data provided by the Internal Revenue Service (IRS). In contrast, we focus on a set of start-up firms that are likely to benefit substantially from access to talented foreign workers. Indeed, the firms in our sample are nearly three times more likely to patent than the firms in Doran et al. The comparison between our results and those of Doran et al. suggests that the contributions of $\mathrm{H}-1 \mathrm{~B}$ visa holders vary across firms, and the effects found in our sample of start-up firms are likely larger than would be found in the overall universe of firms.

\section{Conclusion}

In the U.S., firms can apply for $\mathrm{H}-1 \mathrm{~B}$ visas that allow high-skill foreign workers to enter the U.S. There is a fixed quota of H-1B visas available to for-profit firms, and when the number of applications exceeds the quota the U.S. government holds a lottery that assigns H-1B visas based on computer-generated pseudo-random numbers. The outcome of these $\mathrm{H}-1 \mathrm{~B}$ visa lotteries provides exogenous, random variation in firms' access to skilled foreign workers. In this paper, we examine a sample of start-up firms that applied for $\mathrm{H}-1 \mathrm{~B}$ visas, and compare outcomes based on the firms' win rate in the $\mathrm{H}-1 \mathrm{~B}$ lotteries.

We find that a firm's win rate in the H-1B visa lottery is strongly related to the firm's outcomes over the following three years. Relative to ex ante similar firms that also applied for 
H-1B visas, firms with higher win rates in the lottery are more likely to receive additional external funding and have an IPO or be acquired. Firms with higher win rates also become more likely to secure funding from high-reputation VCs, and receive more patents and more patent citations. Overall, the results show that access to skilled foreign workers has a strong positive effect on firm-level measures of success.

Gourio, Messer, and Siemer (2016) highlight the important role the number of start-ups in a region has in explaining the long-term economic development of that region. Our results show that access to skilled foreign workers leads to improved funding and patenting outcomes for start-up firms, suggesting that improved visa access for such firms could generate significant economic benefits. 


\section{References}

Aghion, Philippe, and Peter Howitt. 1992. A Model of Growth Through Creative Destruction. Econometrica 60, 323-351.

Altonji, Joseph G., Todd E. Elder, and Christopher R. Taber. 2005. Selection on Observed and Unobserved Variables: Assessing the Effectiveness of Catholic Schools. Journal of Political Economy 113, 151-184.

Atanasov, Vladimir, Vladimir Ivanov, and Kate Litvak. 2012. Does Reputation Limit Opportunistic Behavior in the VC Industry? Evidence from Litigation against VCs. Journal of Finance 67, 2215-2246.

Austin, David H. 1993. An Event-Study Approach to Measuring Innovative Output: The Case of Biotechnology. American Economic Review (P\&P) 83, 253-258.

Bena, Jan, and Kai Li. 2014. Corporate Innovation and Mergers and Acquisitions. Journal of Finance 69, 1923-1960.

Bernstein, Shai, Rebecca Diamond, Timothy McQuade, and Beatriz Pousada. 2018. The Contribution of High-Skilled Immigrants to Innovation in the United States. Working paper, Stanford University.

Bernstein, Shai, Xavier Giroud, and Richard R. Townsend. 2016. The Impact of Venture Capital Monitoring. Journal of Finance 71, 1591-1622.

Block, Jörn H., Christian O. Fisch, Alexander Hahn, and Philipp G. Sandner. 2015. Why Do SMEs File Trademarks? Insights from Firms in Innovative Industries. Research Policy 44, 1915-1930.

Bottazzi, Laura, Marco Da Rin, and Thomas Hellman. 2008. Who Are the Active Investors? Evidence from Venture Capital. Journal of Financial Economics 89, 488-512.

Brau, James C., Bill Francis, and Nihon Kohers. 2003. The Choice of IPO versus Takeover: Empirical Evidence. Journal of Business 76, 583-612.

Chang, Xin, Kangkang Fu, Angie Low, and Wenrui Zhang. 2015. Non-Executive Employee Stock Options and Corporate Innovation. Journal of Financial Economics 115, 168-188.

Clemens, Michael. 2013. Why Do Programmers Earn More in Houston than Hyderabad? Evidence from Randomized Processing of U.S. Visas. American Economic Review (P\&P) 103, 198-202.

Dalle, Jean-Michel, Matthijs den Besten, and Carlo Menon. 2017. Using Crunchbase for Economic and Managerial Research. Working paper, OECD.

Dass, Nishant, Vikram Nanda, and Steven Chong Xiao. 2017. Truncation Bias Corrections in Patent Data: Implications for Recent Research on Innovation. Journal of Corporate Finance 44, 353-374. 
Doran, Kirk, Alexander Gelber, and Adam Isen. 2016. The Effects of High-Skilled Immigration Policy on Firms: Evidence from Visa Lotteries. University of Notre Dame, Working paper.

Gompers, Paul A. 1996. Grandstanding in the Venture Capital Industry, Journal of Financial Economics 42, 133-156.

Gourio, Francisco, Todd Messer, and Michael Siemer. 2016. Firm Entry and Macroeconomic Dynamics: A State-level Analysis. American Economic Review 106, 214-218.

Griliches, Zvi. 1990. Patent Statistics as Economic Indicators: A Survey. Journal of Economic Literature 28, 1661-1707.

Hall, Bronwyn H., Adam Jaffe, and Manuel Trajtenberg. 2001. The NBER Patent Citations Data File: Lessons, Insights and Methodological Tools. NBER working paper 8498.

Hall, Bronwyn H., Adam Jaffe, and Manuel Trajtenberg. 2005. Market Value and Patent Citations. RAND Journal of Economics 36, 16-38.

Hochberg, Yael V., Alexander Ljungqvist, and Yang Lu. 2007. Whom You Know Matters: Venture Capital Networks and Investment Performance. Journal of Finance 62, 251-301.

Howell, Sabrina T., 2017. Financing Innovation: Evidence from R\&D Grants. American Economic Review 107, 1136-1164.

Hunt, Jennifer, and Marjolaine Gauthier-Loiselle. 2010. How Much Does Immigration Boost Innovation? American Economic Journal: Macroeconomics 2, 31-56.

Kerr, William R., and William F. Lincoln. 2010. The Supply Side of Innovation: H-1B Visa Reforms and U.S. Ethnic Invention. Journal of Labor Economics 28, 473-508.

Kerr, William R., Josh Lerner, and Antoinette Schoar. 2014. The Consequences of Entrepreneurial Finance: Evidence from Angel Financings. Review of Financial Studies 27, 20-55.

Kogan, Leonid, Dimitris Papanikolaou, Amit Seru, and Noah Stoffman. 2017. Technological Innovation, Resource Allocation, and Growth. Quarterly Journal of Economics 132, 665712.

Lerner, Josh, and Amit Seru. 2017. The Use and Misuse of Patent Data: Issue for Corporate Finance and Beyond. Working paper, Harvard Business School.

Lerner, Josh, Morten Sørensen, and Per Strömberg. 2011. Private Equity and Long-Run Investment: The Case of Innovation. Journal of Finance 66, 445-477.

Ling, Yun. 2016. The Impact of Venture Capital on the Life Cycles of Startups. Working paper, University of Southern California.

Metrick, Andrew, and Ayako Yasuda. 2011. Venture Capital and the Finance of Innovation $2^{\text {nd }}$ Edition, Wiley, New York, NY. 
Oster, Emily. 2019. Unobservable Selection Coefficient Stability: Theory and Evidence. Journal of Business \& Economic Statistics 37, 187-204.

Pakes, Ariel. 1985. On Patents, R\&D, and the Stock Market Rate of Return. Journal of Political Economy 93, 390-409.

Peri, Giovanni, Kevin Shih, and Chad Sparber. 2015. Foreign and Native Skilled Workers: What Can We Learn from H-1B Lotteries? NBER working paper 21175.

Puri, Manju, and Rebecca Zarutskie. 2012. On the Life Cycle Dynamics of Venture-Capital and Non-Venture-Capital-Financed Firms. Journal of Finance 67, 2247-2293.

Romer, Paul M. 1990. Endogenous Technological Change. Journal of Political Economy 98, S71-S102.

Schumpeter, Joseph A. 1942. Capitalism, Socialism, and Democracy. New York: Harper and Brothers.

Seru, Amit. 2014. Firm Boundaries Matter: Evidence from Conglomerates and R\&D Activity. Journal of Financial Economics 111, 381-405.

Sørensen, Morten. 2007. How Smart is Smart Money? A Two-Sided Matching Model of Venture Capital. Journal of Finance 62, 2725-2762.

Trajtenberg, Manuel. 1990. A Penny for Your Quotes: Patent Citations and the Value of Innovation. RAND Journal of Economics 21, 172-187.

Wang, Xinxin. 2017. Catering Innovation: Entrepreneurship and the Acquisition Market. Working paper, University of North Carolina at Chapel Hill.

Zarutskie, Rebecca. 2010. The Role of Top Management Team Human Capital in Venture Capital Markets: Evidence from First Time Funds. Journal of Business Venturing 25, 155172. 
Figure 1: Timeline of Application Process and Variable Measurement

This figure illustrates the timeline of our study using the lottery for fiscal year 2015 as an example. The H-1B visa lottery for fiscal year $t$ are held in the first week of April of fiscal year $t-1$, which is when the win rate is observed. We measure the funding and patenting outcomes during the three-year period starting from October 1 of fiscal year $t$ (i.e., the earliest start date of employment for workers granted an $\mathrm{H}-1 \mathrm{~B}$ visa in the lottery for fiscal year $t$ ). We measure the control variables as of March 31 in fiscal year $t-1$.

\begin{tabular}{|c|c|c|c|}
\hline $\begin{array}{c}\text { 2014/04/07 } \\
\text { H-1B visa lottery }\end{array}$ & \multicolumn{2}{|c|}{$\begin{array}{l}\text { 2014/10/01 - 2017/09/30 } \\
\text { H-1B visa holder eligible to work } \\
\text { Measure dependent variables over this period }\end{array}$} & \\
\hline $\begin{array}{c}\text { 2014/03/31 } \\
\text { Control variables } \\
\text { measured }\end{array}$ & 2015/10/01 & 2016/10/01 & $\begin{array}{l}\text { 2017/09/30 } \\
\text { H-1B visa expires }\end{array}$ \\
\hline $\begin{array}{c}\text { 2014/01/01 } \\
\text { 2014/10/01 } \\
\text { H-1B lottery winners } \\
\text { eligible to begin } \\
\text { working }\end{array}$ & & & 2017/09/30 \\
\hline
\end{tabular}




\section{Figure 2: Histogram of Number of H1-B Visa Applicants}

This figure shows a histogram of the number of $\mathrm{H}-1 \mathrm{~B}$ applicants. The number of applicants is truncated at 10, with the final bar showing the fraction of observations that apply for 10 or more $\mathrm{H}-1 \mathrm{~B}$ visas.

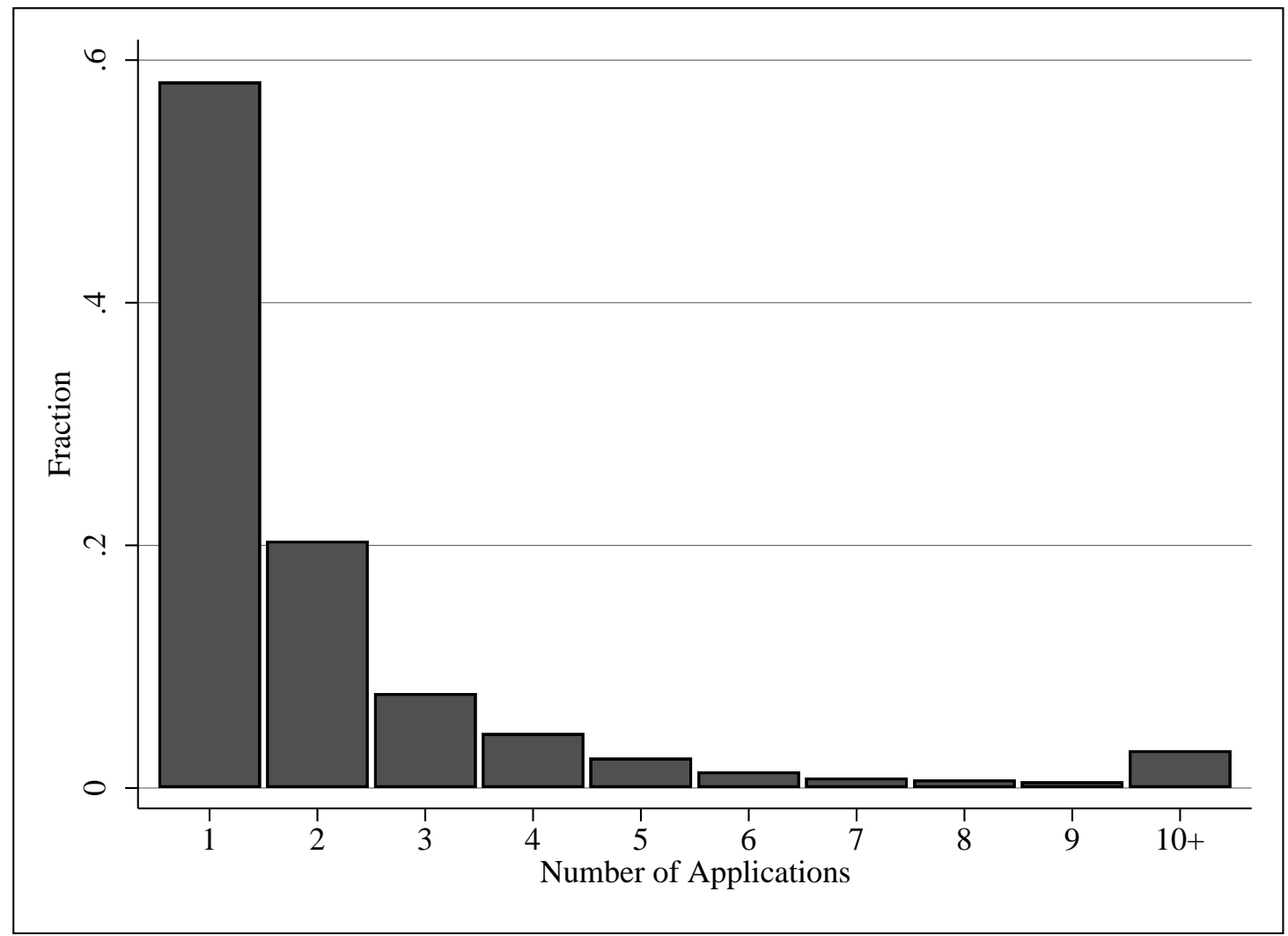


Figure 3: Histogram of H-1B Visa Lottery Win Rates and Funding Outcomes

Panel A shows a histogram of the distribution of Win Rate (the number of $\mathrm{H}-1 \mathrm{~B}$ visas a firm wins through the lottery in a year divided by the number of applicants). Panel B shows a bar chart of the proportion of observations receiving external financing in the three-year post-lottery period for different levels of Win Rate. For Panel B we include only levels of Win Rate for which we have at least 100 observations.

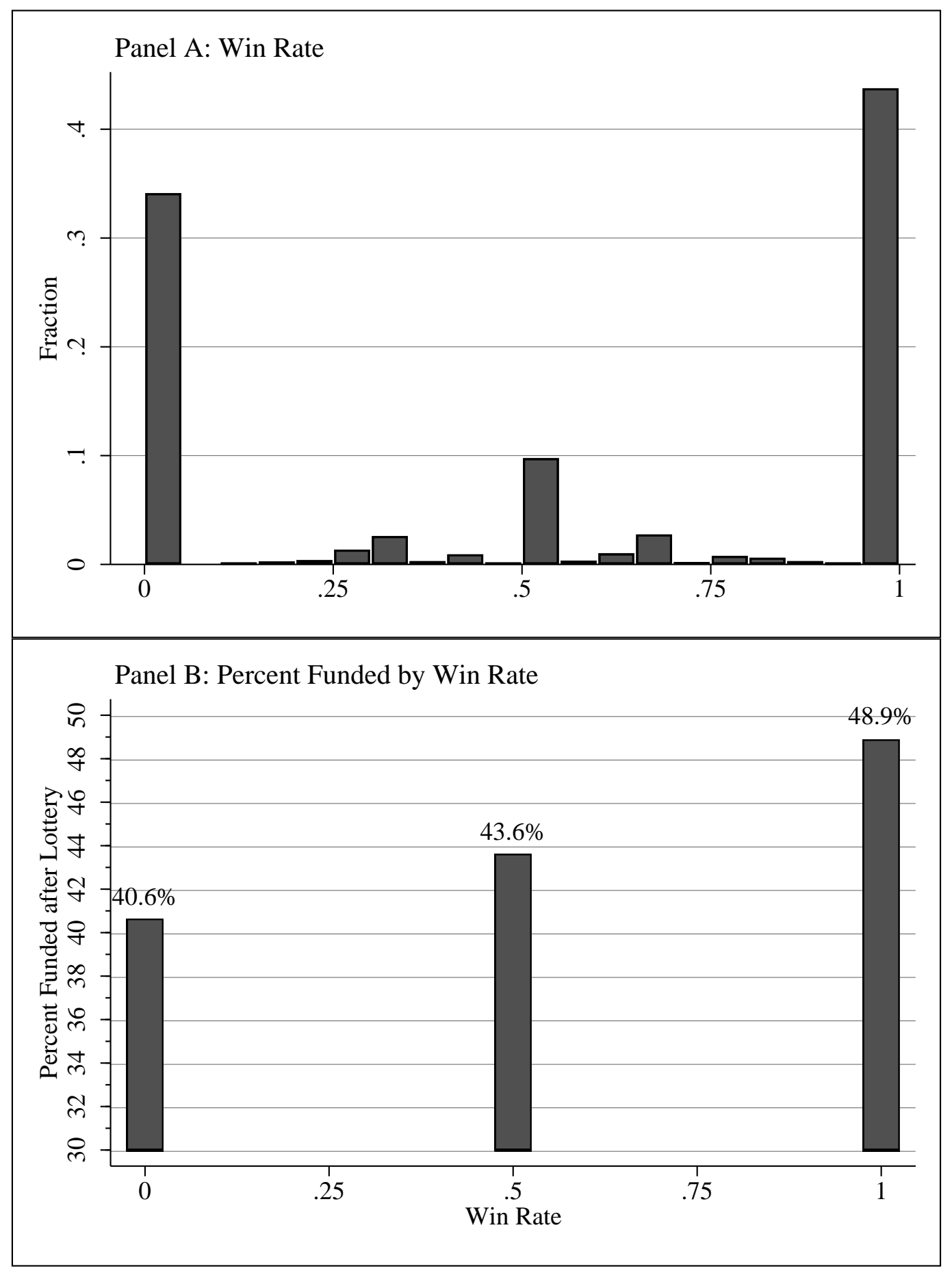




\section{Table 1: Summary Statistics}

This table reports the summary statistics for our sample of firm-years. The sample includes startup firms in Crunchbase that sponsor H-1B petitions in fiscal years 2008, 2009, 2014, and 2015. Number of Applications is the number of $\mathrm{H}-1 \mathrm{~B}$ applicants filed on a Labor Condition Application (LCA) by a firm in a year. Win Rate is the number of $\mathrm{H}-1 \mathrm{~B}$ visas a firm wins through the lottery in a year divided by the number of applicants. Salary is the average annual salary of the applicants sponsored by a firm in a year. Number of Prior Financing Rounds is the number of funding rounds a firm receives before the lottery. Prior Amount Raised is the total amount of funds raised before the lottery. Time Since First Round is the number of months between the first round of funding and the lottery. Time Since Last Round is the number of months between the most recent round of funding and the lottery. Funded is an indicator that equals 100 if a firm receives subsequent external funding in the three years following the lottery and zero otherwise. Funded High Reputation VC is an indicator that equals 100 if a firm receives subsequent funding in the three years following the lottery from a VC firm that is in the top decile of VC firms by age, number of deals, or number of IPOs and zero otherwise. Successful Exit is an indicator variable that equals 100 if the firm goes public or is acquired for at least \$25 million (in 2008 inflation adjusted dollars) in the three years following the lottery and zero otherwise. IPO is an indicator variable that equals 100 if the firm goes public in the three years following the lottery and zero otherwise. Any Patents is an indicator variable that equals 100 if the firm is granted a patent that was applied for in the three years following the lottery and zero otherwise. Number of Patents is the number of patents granted to a firm in the three years following the lottery. Number of Prior Patents is the number of patents granted to a firm in the three years before the H-1B lottery. Number of Adjusted Patents is the category-year mean adjusted number of patents granted to a firm in the three years following the lottery. Total Citations is the number of citations to a firm's patents granted in the three years following the lottery. Total Adjusted Citations is the category-year mean adjusted number of citations summed across the firm's patents granted in the three years following the lottery. Average Number of Citations is the average number of citations to a firm's patents granted in the three years following the lottery. Average Number of Adjusted Citations is the average of the category-year mean adjusted citations on the firm's patents granted in the three years following the lottery. For each variable, we report the mean, standard deviation, $25^{\text {th }}$ percentile, median, and $75^{\text {th }}$ percentile. 


\begin{tabular}{lccccc}
\hline & Mean & Std. Dev. & $25^{\text {th}} \%$ & Median & $7^{\text {th} \%}$ \\
\hline Number of H-1B Applications & 2.5 & 5.1 & 1 & 1 & 2 \\
Win Rate & 0.55 & 0.44 & 0 & 0.55 & 1 \\
Salary (\$) & 85,100 & 29,700 & 65,000 & 80,000 & 100,000 \\
Number of Prior Financing Rounds & 2.8 & 2.0 & 1 & 2 & 4 \\
Prior Amount Raised (\$M) & 40.1 & 90.3 & 5 & 17 & 44 \\
Time Since First Round (months) & 56.0 & 41.7 & 23 & 46 & 81 \\
Time Since Last Round (months) & 26.3 & 30.5 & 7 & 15 & 34 \\
Funded $(\mathrm{t}, \mathrm{t}+2)$ & 44.7 & 49.7 & 0 & 0 & 100 \\
Funded High Reputation VC(t,t+2) & 24.3 & 42.9 & 0 & 0 & 0 \\
Successful Exit $(\mathrm{t}, \mathrm{t}+2)$ & 9.5 & 29.3 & 0 & 0 & 0 \\
IPO(t,t+2) & 4.3 & 20.2 & 0 & 0 & 0 \\
Any Patents(t,t+2) & 32.2 & 46.7 & 0 & 0 & 100 \\
Number of Patents $(\mathrm{t}, \mathrm{t}+2)$ & 5.4 & 65.3 & 0 & 0 & 1 \\
Number of Prior Patents $(\mathrm{t}-3, \mathrm{t}-1)$ & 7.8 & 112 & 0 & 0 & 3 \\
Number of Adjusted Patents $(\mathrm{t}, \mathrm{t}+2)$ & 0.9 & 9.7 & 0 & 0 & 0.2 \\
Total Citations & 186 & 2,142 & 0 & 0 & 8 \\
Total Adjusted Citations & 6.2 & 68.8 & 0 & 0 & 0.3 \\
Average Number of Citations & 9.4 & 34.4 & 0 & 0 & 3.4 \\
Average Number of Adjusted Citations & 0.3 & 1.2 & 0 & 0 & 0.1 \\
\hline
\end{tabular}




\section{Table 2: Win Rate as Dependent Variable}

This table reports regression analysis of the win rate in $\mathrm{H}-1 \mathrm{~B}$ visa lotteries. The dependent variable is Win Rate, which is the number of $\mathrm{H}-1 \mathrm{~B}$ visas a firm wins through the lottery in a year divided by the number of applicants. Column (1) includes federal government fiscal year fixed effects. Column (2) includes industry-city-year fixed effects. All columns include the following firm characteristics: $\log$ (number rounds of financing), $\log$ ( $\$$ amount raised previously), $\log$ (months since first round), $\log$ (months since last round), $\log$ (number of H-1B applications), $\log (\$$ salary for $\mathrm{H}-1 \mathrm{~B}$ positions $)$, and $\log (1+$ number of prior patents $)$. The numbers in brackets are $t$-statistics based on standard errors clustered by firm. $* * *, * *$, and * indicate statistical significance at the 1-percent, 5-percent, and 10-percent levels, respectively.

\begin{tabular}{lrr}
\hline & $(1)$ & $(2)$ \\
\hline $\log$ (\# rounds financing) & -0.02 & -0.01 \\
$\log ($ amount raised) & {$[0.84]$} & {$[0.43]$} \\
& 0.01 & 0.01 \\
$\log ($ months since first round) & {$[0.91]$} & {$[0.96]$} \\
& 0.01 & 0.02 \\
$\log ($ months since last round) & {$[0.40]$} & {$[0.73]$} \\
& -0.02 & -0.02 \\
$\log ($ number of H-1B applications) & {$[1.34]$} & {$[0.89]$} \\
& 0.01 & -0.01 \\
$\log ($ salary) & {$[0.84]$} & {$[0.50]$} \\
& $-0.07 * *$ & -0.04 \\
$\log (1+$ number of prior patents) & {$[2.35]$} & {$[0.77]$} \\
& 0.01 & -0.01 \\
Model F-Stat $p$-value & {$[1.37]$} & {$[0.45]$} \\
Year fixed effects? & 0.16 & 0.84 \\
Industry-City-Year fixed effects? & Yes & Yes \\
$R^{2}$ & No & 0.509 \\
Adjusted- $R^{2}$ & 0.008 & 0.022 \\
Number of Observations & 0.004 & 2,570 \\
\hline
\end{tabular}




\section{Table 3: H-1B Lottery Win Rate and the Probability of Receiving Subsequent Funding}

This table reports regression analysis of the effect of win rate in $\mathrm{H}-1 \mathrm{~B}$ visa lotteries on the probability of receiving subsequent funding. The dependent variable is Funded, which is an indicator that equals 100 if a firm receives subsequent external funding in the three years following the lottery and zero otherwise. The main independent variable is Win Rate, which is the number of $\mathrm{H}-1 \mathrm{~B}$ visas a firm wins through the lottery in a year divided by the number of applicants. Column (1) does not include any control variables or fixed effects. Column (2) includes industry-city-year fixed effects and the following firm controls: log(number rounds of financing), $\log$ ( $\$$ amount raised previously), $\log$ (months since first round), $\log$ (months since last round), $\log$ (number of $\mathrm{H}-1 \mathrm{~B}$ applications), $\log (\$$ salary for $\mathrm{H}-1 \mathrm{~B}$ positions), and $\log (1+$ number of prior patents). The numbers in brackets are $t$-statistics based on standard errors clustered by firm. ${ }^{* * *}, * *$, and $*$ indicate statistical significance at the 1 -percent, 5-percent, and 10 -percent levels, respectively.

\begin{tabular}{lcc}
\hline & $(1)$ & $(2)$ \\
\hline Win Rate & $8.14^{* * *}$ & $9.85^{* * *}$ \\
& {$[3.68]$} & {$[3.18]$} \\
$\log ($ number rounds financing) & & $14.86^{* * *}$ \\
& & {$[3.85]$} \\
$\log ($ amount raised) & & 1.87 \\
& & {$[1.61]$} \\
$\log$ (months since first round) & & $-12.33^{* * *}$ \\
& & {$[4.05]$} \\
$\log ($ months since last round) & & $-5.68^{* * *}$ \\
& & {$[2.64]$} \\
$\log ($ number of H-1B applications) & & $-3.44^{*}$ \\
$\log ($ salary) & & {$[1.79]$} \\
& & 6.84 \\
$\log (1+$ number of prior patents) & & {$[1.37]$} \\
& & 2.05 \\
Industry-City-Year fixed effects? & No & {$[1.37]$} \\
$R^{2}$ & 0.005 & Yes \\
Adjusted- $R^{2}$ & 0.005 & 0.558 \\
Number of Observations & 2,570 & 0.119 \\
\hline
\end{tabular}




\section{Table 4: Venture Capital Funding by High-Reputation Venture Capital Firms}

This table reports regression analysis of the effect of win rate in $\mathrm{H}-1 \mathrm{~B}$ visa lotteries on funding by high-reputation venture capital firms. The dependent variables are equal to 100 if the firm receives funding from a venture capital firm identified as being a highreputation firm based on proxies identified in prior studies (e.g., Atanasov, Ivanov, and Litvak, 2012; Puri and Zarutskie, 2012). In column (1), the venture capital reputation measure is based on the VC firm being in the top decile of firm age. In column (2), the venture capital reputation measure is based on the VC firm being in the top decile by number of deals completed. In column (3), the venture capital reputation measure is based on the VC firm being in the top decile of number of portfolio firms that went public. In column (4), the venture capital reputation measure is based on the VC firm being in the top decile for any of the three preceding measures. The main independent variable is Win Rate, which is the number of H-1B visas a firm wins through the lottery in a year divided by the number of applicants. All specifications include industry-city-year fixed effects and controls for log(number rounds of financing), $\log$ ( $\$$ amount raised previously), $\log$ (months since first round), $\log$ (months since last round), $\log ($ number of $\mathrm{H}-1 \mathrm{~B}$ applications), $\log (\$$ salary for $\mathrm{H}-1 \mathrm{~B}$ positions $)$, and $\log (1+$ number of prior patents). Each specification also controls for whether the firm received funding from a high reputation VC prior to the H1-B visa lottery using the same definition of high reputation VC as that for the dependent variable. The numbers in brackets are $t$-statistics based on standard errors clustered by firm. ${ }^{* * *}$, **, and $*$ indicate statistical significance at the 1-percent, 5-percent, and 10-percent levels, respectively.

\begin{tabular}{|c|c|c|c|c|}
\hline & \multicolumn{4}{|c|}{ Receive Funding from a High-Reputation VC as measured by } \\
\hline & $\frac{\text { VC Age }}{(1)}$ & $\frac{\text { VC Number of Deals }}{(2)}$ & $\frac{\text { VC Number of IPOs }}{(3)}$ & $\frac{\text { VC Composite }}{(4)}$ \\
\hline \multirow[t]{2}{*}{ Win Rate } & $6.26 * *$ & $5.52 * *$ & $5.41 * *$ & $8.23 * * *$ \\
\hline & {$[2.55]$} & {$[2.09]$} & {$[2.09]$} & {$[2.96]$} \\
\hline \multirow[t]{2}{*}{ Received Prior Funding from High-Rep VC? } & $5.72 * *$ & $7.56 * * *$ & $7.47 * * *$ & $7.62 * *$ \\
\hline & {$[2.03]$} & {$[2.67]$} & {$[2.59]$} & {$[2.45]$} \\
\hline Control Variables? & Yes & Yes & Yes & Yes \\
\hline Industry-City-Year fixed effects? & Yes & Yes & Yes & Yes \\
\hline$R^{2}$ & 0.481 & 0.492 & 0.497 & 0.507 \\
\hline Adjusted- $R^{2}$ & -0.035 & -0.014 & -0.003 & 0.017 \\
\hline Number of Observations & 2,570 & 2,570 & 2,570 & 2,570 \\
\hline
\end{tabular}




\section{Table 5: Funding, Successful Exit, and Initial Public Offerings over Time}

This table reports regression analysis of the effect of the win rate in $\mathrm{H}-1 \mathrm{~B}$ lotteries on the probabilities of obtaining additional funding, having a successful exit, and going public during a specified period. In Panel A, the dependent variable is set equal to 100 if the firm obtains external financing. In Panel B, the dependent variable is set equal to 100 if the firm has an IPO or is acquired for at least $\$ 25$ million (in 2008 inflation adjusted dollars). In Panel C, the dependent variable equals 100 if the firm has an IPO. In column (1), the period is one year starting when the H-1B visas from the lottery become valid. In columns (2) and (3), the period is three and five years, respectively. The main independent variable is Win Rate, which is the number of $\mathrm{H}-1 \mathrm{~B}$ visas a firm wins through the lottery in a year divided by the number of applicants. All specifications include industry-city-year fixed effects and controls for $\log$ (number rounds of financing), $\log (\$$ amount raised previously), $\log$ (months since first round), $\log ($ months since last round), $\log ($ number of $\mathrm{H}-1 \mathrm{~B}$ applications), $\log (\$$ salary for $\mathrm{H}-1 \mathrm{~B}$ positions), and $\log (1+$ number of prior patents). The number of observations is 2,570 for each regression. The numbers in brackets are $t$-statistics based on standard errors clustered by firm. $* * *, * *$, and $*$ indicate statistical significance at the 1-percent, 5-percent, and 10-percent levels, respectively.

\begin{tabular}{|c|c|c|c|}
\hline & \multicolumn{3}{|c|}{ Panel A: Funded in } \\
\hline \multirow{3}{*}{ Win Rate } & $\frac{\text { One Year }}{(1)}$ & $\frac{\text { Three Years }}{(2)}$ & $\frac{\text { Five Years }}{(3)}$ \\
\hline & $5.04 *$ & $9.85 * * *$ & $10.56 * * *$ \\
\hline & [1.77] & [3.18] & [3.43] \\
\hline$R^{2}$ & 0.518 & 0.558 & 0.560 \\
\hline Adjusted- $R^{2}$ & 0.041 & 0.119 & 0.124 \\
\hline \multirow{4}{*}{ Win Rate } & \multicolumn{3}{|c|}{ Panel B: Successful Exit in } \\
\hline & $\frac{\text { One Year }}{(1)}$ & $\frac{\text { Three Years }}{(2)}$ & $\frac{\text { Five Years }}{(3)}$ \\
\hline & $1.75 *$ & $2.87 *$ & $6.61 * * *$ \\
\hline & {$[1.82]$} & {$[1.71]$} & {$[3.21]$} \\
\hline$R^{2}$ & 0.510 & 0.530 & 0.527 \\
\hline Adjusted- $R^{2}$ & 0.024 & 0.064 & 0.059 \\
\hline \multicolumn{4}{|c|}{ Panel C: IPO in } \\
\hline \multirow{3}{*}{ Win Rate } & $\frac{\text { One Year }}{(1)}$ & $\frac{\text { Three Years }}{(2)}$ & $\frac{\text { Five Years }}{(3)}$ \\
\hline & 0.83 & $2.05 *$ & $3.48 * *$ \\
\hline & {$[1.22]$} & [1.77] & {$[2.36]$} \\
\hline$R^{2}$ & 0.509 & 0.527 & 0.526 \\
\hline Adjusted- $R^{2}$ & 0.022 & 0.058 & 0.056 \\
\hline
\end{tabular}




\section{Table 6: Patenting Outcomes}

This table reports regression analysis of the effect of win rate in $\mathrm{H}-1 \mathrm{~B}$ visa lotteries on patenting outcomes. All of the patenting outcome variables are based on patents that were applied for, and eventually granted, during the three-year period following the $\mathrm{H}-1 \mathrm{~B}$ lottery. The dependent variables are: $\log (1+$ Number of Patents $), \log (1+$ Adjusted Number of Patents $), \log (1+$ Number of Adjusted Citations $)$, and $\log (1+$ Average Number of Adjusted Citations $)$. The main independent variable is Win Rate, which is the number of $\mathrm{H}-1 \mathrm{~B}$ visas a firm wins through the lottery in a year divided by the number of applicants. All specifications include industry-city-year fixed effects and controls for $\log ($ number rounds of financing), $\log (\$$ amount raised previously), $\log ($ months since first round),

$\log ($ months since last round), $\log ($ number of $\mathrm{H}-1 \mathrm{~B}$ applications), and $\log$ (\$ salary for $\mathrm{H}-1 \mathrm{~B}$ positions). The specifications also include values of the patenting activity used in the dependent variable in the three-year period before the H-1B visa lottery. Panel A includes observations for all sample years. Panel B includes observations for federal government fiscal years 2008 and 2009 only. The numbers in brackets are $t$-statistics based on standard errors clustered by firm. ${ }^{* * *}, * *$, and * indicate statistical significance at the 1 percent, 5-percent, and 10-percent levels, respectively. 


\begin{tabular}{|c|c|c|c|c|}
\hline \multicolumn{5}{|l|}{ Panel A: Full Sample } \\
\hline Dependent variable & $\log (1+\#$ patents $)$ & $\log (1+$ adj. $\#$ patents $)$ & $\underline{\log (1+\text { adj. } \# \text { cites })}$ & log(1+ avg. \# adj. cites $)$ \\
\hline \multirow{3}{*}{ Win Rate } & $(1)$ & $(2)$ & (3) & (4) \\
\hline & $0.11^{* *}$ & $0.06 * * *$ & $0.09 * *$ & $0.03 *$ \\
\hline & {$[2.53]$} & {$[2.59]$} & {$[2.11]$} & {$[1.78]$} \\
\hline \multirow{2}{*}{$\begin{array}{l}\text { Log(patent activity } \\
\text { during prior } 3 \text { years) }\end{array}$} & $0.70 * * *$ & $0.76 * * *$ & $0.73 * * *$ & $0.65 * * *$ \\
\hline & [23.63] & [20.06] & [20.15] & {$[12.09]$} \\
\hline Control Variables? & Yes & Yes & Yes & Yes \\
\hline Industry-City-Year fixed effects? & Yes & Yes & Yes & Yes \\
\hline$R^{2}$ & 0.803 & 0.831 & 0.813 & 0.732 \\
\hline Adjusted- $R^{2}$ & 0.608 & 0.664 & 0.628 & 0.466 \\
\hline Number of Observations & 2,570 & 2,570 & 2,570 & 2,570 \\
\hline \multicolumn{5}{|l|}{ Panel B: 2008 \& 2009 Only } \\
\hline \multirow[t]{2}{*}{ Dependent Variable } & $\log (1+\#$ patents $)$ & $\log (1+$ adj. $\#$ patents $)$ & $\log (1+$ adj. \# cites $)$ & $\log (1+$ avg. $\#$ adj. cites $)$ \\
\hline & $(1)$ & $(2)$ & (3) & $(4)$ \\
\hline \multirow[t]{2}{*}{ Win Rate } & $0.26 * * *$ & $0.15 * * *$ & $0.27 * * *$ & 0.06 \\
\hline & {$[2.65]$} & {$[3.06]$} & {$[2.72]$} & {$[1.51]$} \\
\hline Log(patent activity & $0.80 * * *$ & $0.89 * * *$ & $0.76 * * *$ & $0.65 * * *$ \\
\hline during prior 3 years) & [14.90] & {$[10.61]$} & [13.05] & [6.86] \\
\hline Control Variables? & Yes & Yes & Yes & Yes \\
\hline Industry-City-Year fixed effects? & Yes & Yes & Yes & Yes \\
\hline$R^{2}$ & 0.810 & 0.839 & 0.810 & 0.734 \\
\hline Adjusted- $R^{2}$ & 0.556 & 0.624 & 0.555 & 0.378 \\
\hline Number of Observations & 825 & 825 & 825 & 825 \\
\hline
\end{tabular}




\section{Internet Appendix Table 1: \\ Comparison of Crunchbase Firms that File versus Do Not File LCAs}

This table compares firms in the Crunchbase dataset that file LCAs with those that do not file LCAs. LCA filers are the firms in our sample. Non-filers are firms in Crunchbase that satisfy the following conditions: (1) the firm is a private firm based in the U.S., (2) it has completed at least one round of external financing in the previous 60 months, (3) the dollar amount of the prior external financing is available, and (4) the firm does not file LCAs for new employment in the given fiscal year. The table reports the means for various characteristics of the two groups of firms. Number of Prior Financing Rounds is the number of funding rounds a firm receives before the lottery. Prior amount Raised is the total amount of funds raised before the lottery. Time Since First Round is the number of months between the first round of funding and the lottery. Time Since Last Round is the number of months between the most recent round of funding and the lottery. Funded is an indicator that equals 100 if a firm receives subsequent external funding in the three years following the lottery and zero otherwise. Funded High Reputation VC is an indicator that equals 100 if a firm receives subsequent funding in the three years following the lottery from a VC firm that is in the top decile of VC firms by age, number of deals, or number of IPOs. IPO is an indicator variable that equals 100 if the firm goes public in the three years following the lottery and zero otherwise. ${ }^{* * *}, * *$, and $*$ (displayed in the second column) indicate the statistical significance of the difference in means between the two samples at the 1-percent, 5-percent, and 10-percent levels, respectively.

\begin{tabular}{|c|c|c|}
\hline & LCA Filers & Non-Filers \\
\hline Number of Prior Financing Rounds & 2.8 & $2.1 * * *$ \\
\hline Prior Amount Raised (\$M) & 40.1 & $15.1 * * *$ \\
\hline Time Since First Round (months) & 56.0 & $38.2 * * *$ \\
\hline Time Since Last Round (months) & 26.3 & $20.5 * * *$ \\
\hline Funded $_{(t, t+2)}$ & 44.7 & $32.5 * * *$ \\
\hline Funded High Reputation $\mathrm{VC}_{(\mathrm{t}, \mathrm{t}+2)}$ & 24.3 & $13.3^{* * *}$ \\
\hline $\mathrm{IPO}_{(\mathrm{t}, \mathrm{t}+2)}$ & 4.3 & $1.1^{* * *}$ \\
\hline
\end{tabular}




\section{Internet Appendix Table 2:}

\section{False Negative and False Positive Rates by LCA Submission Month}

This table reports, for each month from December 2016 through April 2017, the number of workers filing LCAs for new employment, the share of all LCAs filed that are for new employment, the false negative rate, and the false positive rate. A false negative is defined as an LCA for new employment that does not have a start date that is five to six months in the future. A false positive is defined as an LCA with a start date five to six months in the future that is not for new employment.

\begin{tabular}{lcccc}
\hline & $\begin{array}{c}\text { \# of workers filing } \\
\text { for new employment }\end{array}$ & $\begin{array}{c}\text { New employment } \\
\text { share of all LCAs }\end{array}$ & $\begin{array}{c}\text { False } \\
\text { negative rate }\end{array}$ & $\begin{array}{c}\text { False } \\
\text { positive rate }\end{array}$ \\
\hline December & 21 & $9.7 \%$ & $90.5 \%$ & $84.6 \%$ \\
January & 64 & $22.5 \%$ & $29.7 \%$ & $34.8 \%$ \\
February & 1,150 & $82.4 \%$ & $1.4 \%$ & $5.9 \%$ \\
March & 2,292 & $78.5 \%$ & $1.7 \%$ & $10.5 \%$ \\
April & 18 & $6.0 \%$ & $83.3 \%$ & $96.7 \%$ \\
\hline
\end{tabular}




\section{Internet Appendix Table 3: \\ H-1B Lottery Win Rate and the Probability of Receiving Subsequent Funding: \\ Alternative Application Windows}

This table reports regression analysis of the effect of win rate in $\mathrm{H}-1 \mathrm{~B}$ visa lotteries on the probability of receiving subsequent funding. The dependent variable is Funded, which is an indicator that equals 100 if a firm receives subsequent external funding in the three years following the lottery and zero otherwise. The main independent variable is Win Rate, which is the number of $\mathrm{H}-1 \mathrm{~B}$ visas a firm wins through the lottery in a year divided by the number of applicants. In columns (1) and (2), the number of applications is measured using LCA filings in January through March of the prior fiscal year (as opposed to February through March as in Table 3). In columns (3) and (4), the number of applications is measured using LCA filings in December through March of the prior fiscal year. The even numbered columns include industrycity-year fixed effects and the following firm controls: log(number rounds of financing), $\log (\$$ amount raised previously), $\log$ (months since first round), $\log$ (months since last round), $\log$ (number of $\mathrm{H}-1 \mathrm{~B}$ applications), $\log (\$$ salary for $\mathrm{H}-1 \mathrm{~B}$ positions $)$, and $\log (1+$ number of prior patents). The numbers in brackets are $t$-statistics based on standard errors clustered by firm. $* * *, * *$, and * indicate statistical significance at the 1-percent, 5-percent, and 10-percent levels, respectively.

\begin{tabular}{lccccc}
\hline & \multicolumn{2}{c}{ January - March } & & \multicolumn{2}{c}{ December - March } \\
\cline { 2 - 3 } \cline { 5 - 6 } & $(1)$ & $(2)$ & & $(3)$ & $(4)$ \\
\hline Win Rate & $8.67^{* * *}$ & $10.24^{* * *}$ & & $8.62^{* * *}$ & $10.09^{* * *}$ \\
& {$[3.97]$} & {$[3.33]$} & & {$[3.94]$} & {$[3.27]$} \\
Control Variables? & No & Yes & & No & Yes \\
Industry-City-Year fixed effects? & No & Yes & & No & Yes \\
$R^{2}$ & 0.006 & 0.558 & & 0.006 & 0.558 \\
Adjusted- $R^{2}$ & 0.006 & 0.119 & & 0.006 & 0.119 \\
Number of Observations & 2,615 & 2,615 & & 2,617 & 2,617 \\
\hline
\end{tabular}




\section{Internet Appendix Table 4: Logit and Conditional Logit Results}

This table reports robustness tests of the regression analysis of the effect of win rate in $\mathrm{H}-1 \mathrm{~B}$ visa lotteries on the probability of receiving subsequent funding. The dependent variable is Funded, which is an indicator that equals 100 if a firm receives external funding in the three years following the lottery and zero otherwise. The main independent variable is Win Rate, which is the number of $\mathrm{H}-1 \mathrm{~B}$ visas a firm wins through the lottery in a year divided by the number of applicants. Column (1) reports results from a logit model. Column (2) reports results from a conditional logit model that conditions out the effect of industry-city-year effects and includes the following firm controls: $\log$ (number rounds of financing), $\log (\$$ amount raised previously), $\log$ (months since first round), $\log$ (months since last round), $\log$ (number of $\mathrm{H}-1 \mathrm{~B}$ applications), $\log$ ( $\$$ salary for H-1B positions), and $\log (1+$ number of prior patents $)$. The number in brackets is a robust $z$-score. $* * *, * *$, and $*$ indicate statistical significance at the 1-percent, 5-percent, and 10 -percent levels, respectively.

\begin{tabular}{|c|c|c|}
\hline Estimation Method & $\frac{\text { Logit }}{(1)}$ & $\frac{\text { Conditional Logit }}{(2)}$ \\
\hline Win Rate & $\begin{array}{l}0.33^{* * *} \\
{[3.69]}\end{array}$ & $\begin{array}{c}0.44^{* * *} \\
{[3.15]}\end{array}$ \\
\hline Control Variables? & No & Yes \\
\hline Industry-City-Year fixed effects? & No & Yes \\
\hline Pseudo- $R^{2}$ & 0.004 & 0.125 \\
\hline Number of Observations & 2,570 & 2,570 \\
\hline
\end{tabular}

